\title{
Hydrogen sulfide suppresses angiotensin II-stimulated endothelin-1 generation and subsequent cytotoxicity-induced endoplasmic reticulum stress in endothelial cells via NF-кB
}

\author{
HENG-JING HU ${ }^{1}$, ZHI-SHENG JIANG ${ }^{2}$, SHENG-HUA ZHOU ${ }^{1}$ and QI-MING LIU ${ }^{1}$ \\ ${ }^{1}$ Department of Cardiology/Cardiac Catheterization Laboratory, Second Xiangya Hospital, Central South University, \\ Changsha, Hunan 410011; ${ }^{2}$ Institute of Cardiovascular Disease and Key Laboratory for Arteriosclerology of Hunan, \\ University of South China, Hengyang, Hunan 421001, P.R. China
}

Received September 12, 2015; Accepted August 9, 2016

DOI: $10.3892 / \mathrm{mmr} .2016 .5827$

\begin{abstract}
The effects of hydrogen sulfide $\left(\mathrm{H}_{2} \mathrm{~S}\right)$ and the nuclear factor $\kappa \mathrm{B}(\mathrm{NF}-\kappa \mathrm{B})$ signaling pathway in angiotensin II (AngII)-induced endothelin-1 (ET-1) expression and subsequent cytotoxicity remain unclear. The present study aimed to investigate the hypothesis that $\mathrm{H}_{2} \mathrm{~S}$ protects human umbilical vein endothelial cells (HUVECs) against AngII-stimulated ET-1 generation and subsequent cytotoxicity-induced endoplasmic reticulum stress via the NF- $\mathrm{KB}$ signaling pathway. The results of the present study demonstrated that AngII significantly upregulated the expression levels of ET-1, glucose-regulated protein 78 , CCAAT-enhancer-binding protein homologous protein, phosphorylated (p)-p65 and inducible nitric oxide synthase; stimulated nitric oxide production; suppressed the expression and activity of cystathionine- $\gamma$-lyase (CSE), a $\mathrm{H}_{2} \mathrm{~S}$ synthetase; and decreased cell viability. Conversely, BQ788 (an ET-1 receptor antagonist) exhibited an inhibitory effect on the AngII-mediated suppression of CSE expression and activity in HUVECs. The effects of AngII were abrogated by sodium hydrosulfide ( $\mathrm{NaHS}$, an $\mathrm{H}_{2} \mathrm{~S}$ donor), BQ788 or pyrrolidinedithiocarbamic acid (PDTC, an inhibitor of NF- $\kappa B$ ). Furthermore, pretreatment with NaHS or PDTC attenuated AngII-induced apoptosis and cleaved caspase-12 generation. The pretreatment of HUVECs with BQ788 prior to AngII exposure mimicked the inhibitory effect of NaHS on the expression of p-p65 induced by AngII. In conclusion, the present study provides evidence that exogenous $\mathrm{H}_{2} \mathrm{~S}$ attenuates AngII-induced inflammation and cytotoxicity via inhibition of the ET-1/NF-kB signaling pathway in HUVECs.
\end{abstract}

Correspondence to: Professor Qi-Ming Liu, Department of Cardiology/Cardiac Catheterization Laboratory, Second Xiangya Hospital, Central South University, 139 Middle Renmin Road, Changsha, Hunan 410011, P.R. China

E-mail: qimingliuxiangya@hotmail.com

Key words: hydrogen sulfide, angiotensin II, endothelin-1, nuclear factor- $\kappa \mathrm{B}$

\section{Introduction}

Atherosclerosis (AS), which is a common disorder with increasing prevalence worldwide, results in the progressive decline in the function of multiple organs, with the most serious effect being an increased risk of cardiovascular events and mortality (1). However, the mechanisms underlying development of AS remain unclear. Endothelial dysfunction (ED) resulting from inflammation is crucial throughout the development of AS $(2,3)$. Previous studies using experimental models of AS and diabetes revealed that the accumulation of cholesterol-rich lipoproteins in the artery wall results in ED (4-7). ED is predominantly mediated by endothelin-1 (ET-1) (4-7), which is a potent endothelial injury factor secreted by human umbilical vein endothelial cells (HUVECs).

The renin-angiotensin system (RAS) is important for vascular homeostasis. Activation of the RAS product, angiotensin II (AngII) is associated with arterial wall remodeling (8), and AngII is one of the central vasoactive signaling molecules in ED progression (9). AngII is involved in various pathological conditions, including hypertension, diabetes and AS (10-12). In addition, high concentrations of AngII result in necrosis and apoptosis of HUVECs (13).

Protein translation, folding and trafficking occur in the endoplasmic reticulum (ER), and this organelle responds early to cellular stress (14). ER stress is caused by numerous factors, including oxidative stress, hypoxia and exposure to chemicals, including AngII (15). Numerous studies have revealed that AS, diabetes mellitus, inflammatory conditions and cardiovascular disorders are associated with ER stress induction $(16,17)$.

The signal transduction pathway associated with AngII-induced inflammation in endothelial cells has been investigated. Guo et al (18) demonstrated that the nuclear factor $\kappa \mathrm{B}(\mathrm{NF}-\kappa \mathrm{B})$ signaling pathway is involved in AngII-induced HUVEC dysfunction. Therefore, molecules that inhibit activation of the NF- $\mathrm{kB}$ signaling pathway may be beneficial for the treatment of AngII-induced ED.

Hydrogen sulfide $\left(\mathrm{H}_{2} \mathrm{~S}\right)$ was originally identified as a gasotransmitter in the cardiovascular system (19); however, several biological functions of $\mathrm{H}_{2} \mathrm{~S}$ have now been demonstrated, including a potential role in endothelial cell protection (19). 
$\mathrm{H}_{2} \mathrm{~S}$ is primarily produced by three constitutively expressed enzymes: Cystathionine- $\gamma$-lyase (CSE), cystathionine $\beta$-synthase and 3-mercaptopyruvate sulphurtransferase (20). Endogenous $\mathrm{H}_{2} \mathrm{~S}$ has important regulatory roles in cardiovascular function. CSE-knockout mice have markedly reduced $\mathrm{H}_{2} \mathrm{~S}$ production in the aorta, heart and serum, and develop pronounced hypertension (21). Evidence suggests that $\mathrm{H}_{2} \mathrm{~S}$ is an important regulator of inflammation, and may inhibit $\mathrm{H}_{2} \mathrm{O}_{2}$-induced production of inflammatory mediators by endothelial cells (22), including interleukin-6 and tumor necrosis factor- $\alpha(23,24)$. Certain studies have demonstrated that $\mathrm{H}_{2} \mathrm{~S}$ exerts antiatherogenic (25) and antioxidant (26) effects. However, the mechanisms underlying $\mathrm{H}_{2} \mathrm{~S}$ regulation of inflammatory molecule production remain unclear.

In the present study, HUVECs were treated with AngII to establish an in vitro cytotoxicity model. The aim of the present study was to investigate the following: i) Whether ER stress, NF- $\kappa$ B and ET-1 were involved in AngII-induced cytotoxicity; ii) whether inhibition of the $\mathrm{CSE} / \mathrm{H}_{2} \mathrm{~S}$ pathway was associated with AngII-induced cytotoxicity; and, if so, iii) whether supplementation of exogenous $\mathrm{H}_{2} \mathrm{~S}$ suppressed AngII-induced cytotoxicity via inhibition of ER stress, inducible nitric oxide synthase (iNOS)/nitric oxide (NO) and ET-1; and iv) whether supplementation of exogenous $\mathrm{H}_{2} \mathrm{~S}$ inhibited AngII-induced ER stress via suppression of the ET-1/NF- $\mathrm{B}$ signaling pathway.

\section{Materials and methods}

Materials. Dulbecco's modified Eagle's medium (DMEM) and fetal bovine serum (FBS) were obtained from Gibco; Thermo Fisher Scientific, Inc. (Waltham, MA, USA). Sodium hydrosulfide (NaHS), AngII, pyrrolidinedithiocarbamic acid (PDTC), BQ788, Nitrite Detection kit, Hoechst 33258 and terminal deoxynucleotidyl transferase mediated dUTP nick end labeling (TUNEL) In Situ Cell Death Detection kit were purchased from Sigma-Aldrich (St. Louis, MO, USA). Antibodies against ET-1 (cat. no. ab2786), iNOS (cat. no. ab3523), total p65 (cat. no. ab16502), phosphorylated (p)-p65 (cat. no. ab86299), caspase-12 (cat. no. ab62484), glucose-regulated protein 78 (GRP78; cat. no. ab21685) and CCAAT-enhancer-binding protein homologous protein (CHOP; cat. no. ab11419) and glyceraldehyde 3-phosphate dehydrogenase (GAPDH; cat. no. ab8245) were provided by Abcam (Cambridge, UK). The anti-CSE antibody was provided by ProteinTech Group, Inc. (Chicago, IL, USA; cat. no. 12,032-1-AP). Horseradish peroxidase-conjugated $\mathrm{IgG}(\mathrm{H}+\mathrm{L})$ secondary antibodies were purchased from the Beyotime Institute of Biotechnology (Shanghai, China; cat. nos. A0192 and A0208). Cell Counting kit-8 (CCK-8) was purchased from Dojindo Molecular Technologies, Inc. (Shanghai, China). All other reagents, unless specified, were purchased from Beyotime Institute of Biotechnology.

Cell culture and treatments. HUVECs were obtained from The Cell Bank of Type Culture Collection of Chinese Academy of Sciences (Shanghai, China), and cultured in DMEM supplemented with $10 \% \mathrm{FBS}$ at $37^{\circ} \mathrm{C}$ in a humidified atmosphere containing $5 \% \mathrm{CO}_{2}$. Prior to every experiment, the medium was replaced with fresh serum-containing medium, unless indicated.
Cells were divided into the following treatment groups: Untreated; AngII, consisting of $1 \times 10^{6}$ HUVEC cells treated with $10^{-6} \mathrm{M}$ AngII for 0-24 h; PDTC+AngII, consisting of $1 \times 10^{6}$ cells exposed to $100 \mu \mathrm{M}$ PDTC for 60 min prior to treatment with $10^{-6} \mathrm{M}$ AngII for $24 \mathrm{~h}$; NAHS+AngII, consisting of $1 \times 10^{6}$ cells exposed to $200-400 \mu \mathrm{mol} / 1$ NAHS for $60 \mathrm{~min}$ prior to treatment with $10^{-6} \mathrm{M}$ AngII for $24 \mathrm{~h}$; AngII+BQ788, consisting of $1 \times 10^{6}$ cells exposed to $1 \mathrm{nM}$ or $1 \mu \mathrm{M}$ BQ788 for $24 \mathrm{~h}$ and $60 \mathrm{~min}$, respectively, prior to treatment with $10^{-6} \mathrm{M}$ AngII for $24 \mathrm{~h}$; and AngII+ET-1, consisting of $1 \times 10^{6}$ cells exposed to $1 \mathrm{nM}$ ET-1 for $0-24 \mathrm{~h}$ prior to treatment with $10^{-6} \mathrm{M}$ AngII for $24 \mathrm{~h}$.

Cell viability assay. HUVECs cells were seeded in 96-well plates at a density of $1 \times 10^{6}$ cells/well prior to treatment with various agents. Following this, a solution of $100 \mu \mathrm{l} \mathrm{CCK-8} \mathrm{was}$ added into each well at a 1:10 dilution and the treated plates were incubated for a further $2 \mathrm{~h}$ at $37^{\circ} \mathrm{C}$. Absorbance was measured at $450 \mathrm{~nm}$ with a microplate reader. The mean optical density (OD) of four wells for each group was used to calculate the percentage cell viability according to the following formula: Percentage cell viability $=(\mathrm{OD}$ treatment group / OD control group $) \times 100$.

NO determination in culture supernatants. Nitrite, a marker for the production of $\mathrm{NO}$, was measured in culture supernatants using a Nitrite Detection kit. Briefly, $50 \mu \mathrm{l}$ aliquots of cell culture medium from each dish were collected and mixed with $100 \mu \mathrm{l}$ Griess reagent (50 $\mu \mathrm{l} 1 \%$ sulfanilamide $50 \mu \mathrm{l} 0.1 \%$ naphthylethylenediamine dihydrochloride in $2.5 \% \mathrm{H}_{3} \mathrm{PD}_{4}$ ) in 96-well microtiter plates. The absorbance of $\mathrm{NO}_{2}$ was measured at $520 \mathrm{~nm}$ with a microplate reader.

Measurement of CSE activity. Following treatment, the HUVECs were collected and homogenized in $50 \mathrm{mM}$ ice-cold potassium phosphate buffer ( $\mathrm{pH}$ 6.8). The reaction mixture [100 mmol/l potassium phosphate buffer $(\mathrm{pH} 7.4), 10 \mathrm{mmol} / 1$ L-cysteine, $2 \mathrm{mmol} / 1$ pyridoxal 5'-phosphate, and $10 \%(\mathrm{w} / \mathrm{v})$ homogenate] was added to Erlenmeyer flasks, along with the center wells ( $2 \mathrm{ml}$ cryovial test tubes containing $0.5 \mathrm{ml} 1 \%$ zinc acetate as the trapping solution and a $2 \times 2.5 \mathrm{~cm}$ filter paper to increase the air/liquid contact surface). The flasks were then flushed with $\mathrm{N}_{2}$ and sealed with a double layer of parafilm. The reactions were initiated by transferring the flasks from ice to a $37^{\circ} \mathrm{C}$ shaking water bath. After $90 \mathrm{~min}, 0.5 \mathrm{ml} \mathrm{50 \%}$ trichloroacetic acid was added to terminate the reaction. The flasks were resealed and incubated at $37^{\circ} \mathrm{C}$ for a further $60 \mathrm{~min}$ to ensure the complete trapping of $\mathrm{H}_{2} \mathrm{~S}$ released from the reaction mixture. Following this, the contents of the center wells were transferred to test tubes containing $3.5 \mathrm{ml}$ water. Subsequently, $0.5 \mathrm{ml} 20 \mathrm{mM} N, N$-dimethyl- $p$-phenylenediamine sulfate in $7.2 \mathrm{M} \mathrm{HCl}$ was added, immediately followed by $0.5 \mathrm{ml}$ $30 \mathrm{mM} \mathrm{FeCl}_{3}$ in $1.2 \mathrm{M} \mathrm{HCl}$. The absorbance of the resulting solution was measured at $670 \mathrm{~nm} 20$ min later using a spectrophotometer.

Western blot analysis. Following treatment, the cells were washed three times with phosphate-buffered saline (PBS) and lysed in lysis buffer consisting of $1 \mathrm{ml}$ radioimmunopreciptation assay lysis buffer, $25 \mu \mathrm{g} / 1$ phenylmethylsulfonyl fluoride and $110 \mathrm{mU}$ PhosSTOP phosphatase inhibitor (Sigma-Aldrich) 
on ice for $30 \mathrm{~min}$. The resulting cell lysates were centrifuged at $10,943 \times \mathrm{g}$ for $15 \mathrm{~min}$ at $4^{\circ} \mathrm{C}$. Proteins were quantified using the bicinchoninic acid method according to the manufacturer's protocol (Beyotime Institute of Biotechnology).

Total proteins (300 ng) were separated by $10 \%$ sodium dodecyl sulfate-polyacrylamide gel electrophoresis and were transferred to polyvinylidene difluoride membranes via electroblotting. The membranes were blocked with 5\% (w/v) non-fat milk powder and $0.1 \%$ (v/v) Tween 20 for $1 \mathrm{~h}$, and were then incubated with ET-1 (1:200), CSE $(1: 1,000)$, p-p65 (1:2,000), iNOS (1:2,000), CHOP $(1: 2,000)$, caspase-12 $(1: 2,000)$, GRP78 (1:800), GAPDH $(1: 1,000)$ and total p65 $(1: 1,000)$ primary antibodies overnight at $4^{\circ} \mathrm{C}$. Following three washes in Tris-buffered saline with $0.1 \%$ Tween 20 , the membranes were incubated with the corresponding secondary antibodies (dilution, 1:1,000) for $1 \mathrm{~h}$ at room temperature. Membranes were visualized using an enhanced chemiluminescence kit according to the manufacturer's instructions (Beyotime Institute of Biotechnology). Relative protein expression levels were semi-quantitatively analyzed by densitometry using Quantity One software (version, 4.62; Bio-Rad Laboratories, Inc., Hercules, CA, USA).

Hoechst 33258 and TUNEL staining to assess HUVEC apoptosis. HUVEC apoptosis following treatment was detected by TUNEL and Hoechst 33258 staining. TUNEL staining was performed using an In Situ Cell Death Detection kit according to the manufacturer's protocol. Cells $\left(1 \times 10^{6}\right)$ in culture plates were fixed with $4 \%$ paraformaldehyde in PBS for $10 \mathrm{~min}$. Following three washes in PBS, cells were stained with $50 \mu 1$ TUNEL dye for $1 \mathrm{~h}$, rinsed briefly with PBS and air-dried. Cells were visualized under a florescence microscope. Apoptotic cells with condensed nuclei fluoresced green fluorescence, whereas viable cells exhibited normal nuclear size and were not florescent. Quantitative analysis of the mean fluorescence intensity of each group was performed using ImageJ software (version, 1.41o; National Institutes of Health, Bethesda, MD, USA).

In addition, Hoechst 33258 staining was performed using an In Situ Cell Death Detection kit according to the manufacturer's protocol. Cells were fixed with $4 \%$ paraformaldehyde in PBS for $10 \mathrm{~min}$. Following three washes in PBS, cells were stained with $5 \mathrm{mg} / \mathrm{l}$ Hoechst 33258 dye for $10 \mathrm{~min}$, rinsed briefly with PBS and air-dried. Cells were visualized under a florescence microscope. Apoptotic cells with condensed nuclei fluoresced blue, whereas viable cells exhibited normal nuclear size and weak florescence. Quantitative analysis of the mean fluorescence intensity of each group was performed as for TUNEL staining.

Statistical analysis. All data are presented as the mean \pm standard error of the mean. Differences between groups were analyzed using one-way analysis of variance followed by the Bonferroni correction method, which was performed using the SPSS software program (version, 15.0; SPSS, Inc., Chicago, IL, USA). $\mathrm{P}<0.05$ was considered to indicate a statistically significant difference.

\section{Results}

AngII induces cytotoxicity via triggering ER stress and inducing the expression of NF- $\mathrm{B}$ and ET-1 in HUVECs.
Since iNOS, NO, ET-1 and CSE have been demonstrated to be involved in AngII-induced cytotoxicity (27-29) and increased levels of p-p65 (30), western blotting was performed to analyze the expression levels of these proteins in AngII-treated HUVECs. As presented in Fig. 1, untreated HUVECs produced low levels of ET-1 (Fig. 1A), iNOS (Fig. 1B), p-p65 (Fig. 1C), CHOP (Fig. 1D) and GRP78 (Fig. 1E), which increased significantly following AngII treatment in a time-dependent manner. The expression levels (Fig. 1F) and activity (Fig. 1G) of CSE decreased significantly in a time-dependent manner following AngII treatment, whereas nitrite production (Fig. 1H) was significantly increased.

ET-1 mediates AngII-induced inhibitory effects on the expression level and activity of CSE in HUVECs. AngII affects endothelial cells primarily via the activation of genes associated with inflammation, such as ET-1 (31). The present study investigated whether ET-1 activity contributed to the inhibition of CSE expression and activity mediated by AngII (Fig. 2). HUVECs were preconditioned with a well-known ET-1 receptor antagonist, BQ788, prior to AngII treatment. Pretreatment of cells with $1 \mu \mathrm{M}$ BQ788 significantly attenuated AngII-induced downregulation of CSE expression (Fig. 2A) and activity (Fig. 2C). In addition, similar to the AngII results, treatment of HUVECs with ET-1 significantly suppressed CSE expression (Fig. 2B) and activity (Fig. 2D) in a time-dependent manner. These data suggest that ET-1 contributes to AngII-induced downregulation of the expression and activity of CSE in HUVECs.

Exogenous treatment with $\mathrm{H}_{2} \mathrm{~S}$ and ET-1 inhibitor reduces cytotoxicity via suppressing ER stress, iNOS/NO and ET-1 in AngII-treated HUVECs. Since AngII-induced cytotoxicity results in a decrease in CSE expression and activity, and therefore a decrease in endogenous $\mathrm{H}_{2} \mathrm{~S}$ production, the protective effects of exogenous $\mathrm{H}_{2} \mathrm{~S}$ on AngII-induced inflammatory responses were investigated. As presented in Fig. 3, pretreatment of HUVECs with NaHS for $1 \mathrm{~h}$ prior to AngII exposure significantly attenuated the increased levels of ET-1 (Fig. 3A), iNOS (Fig. 3B), GRP78 (Fig. 3C), CHOP (Fig. 3D) and nitrite (Fig. 3E) induced by $10^{-6} \mathrm{M}$ AngII treatment for $24 \mathrm{~h}$, in a dose-dependent manner. The decrease in cell viability induced by $10^{-6} \mathrm{M}$ AngII treatment for $24 \mathrm{~h}$ was significantly abrogated, in a dose-dependent manner, by pretreatment with NaHS for $1 \mathrm{~h}$ prior to AngII exposure (Fig. 3F).

Similarly, as presented in Fig. 4, pretreatment of cells with $1 \mu \mathrm{M}$ BQ788 for $1 \mathrm{~h}$ prior to $10^{-6} \mathrm{M}$ AngII exposure abrogated the increased production of ET-1 (Fig. 4A), iNOS (Fig. 4B), GRP78 (Fig. 4C), CHOP (Fig. 4D) and nitrite (Fig. 4E), and significantly attenuated the decreased cell viability induced by $10^{-6} \mathrm{M}$ AngII treatment for $24 \mathrm{~h}$ (Fig. 4F). BQ788 treatment alone did not affect the basal levels of ET-1, iNOS, GRP78, CHOP or nitrite in HUVECs. These findings suggest that pretreatment with an ET-1 inhibitor had a similar cytoprotective effect to the $\mathrm{H}_{2} \mathrm{~S}$ donor NaHS on AngII-induced cytotoxicity. Therefore, the activation of ET-1, GRP78, CHOP, iNOS, enhancement of nitrite production and decrease in cell viability may be involved in AngII-induced cytotoxicity in HUVECs.

Exogenous $\mathrm{H}_{2} \mathrm{~S}$ and an $\mathrm{NF}-\kappa \mathrm{B}$ inhibitor attenuate AngII-induced cytotoxicity in HUVECs. As presented in 
A

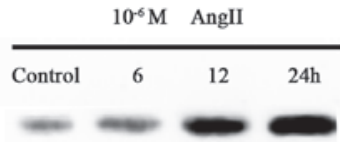

GAPDH
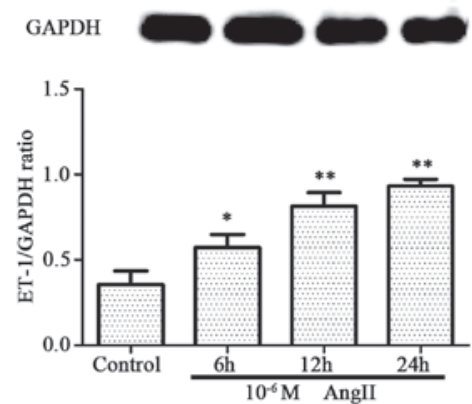

C
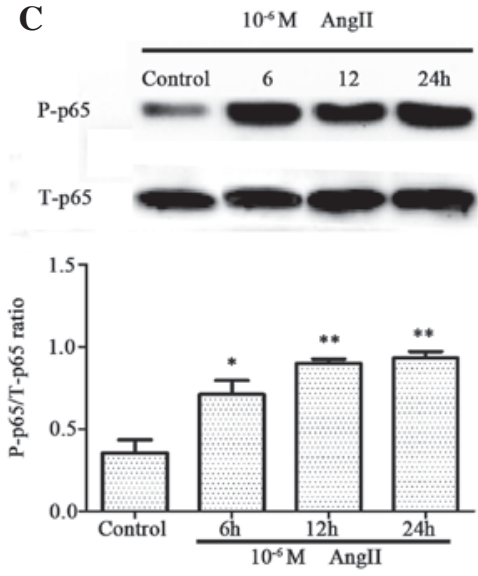

$\mathbf{E}$
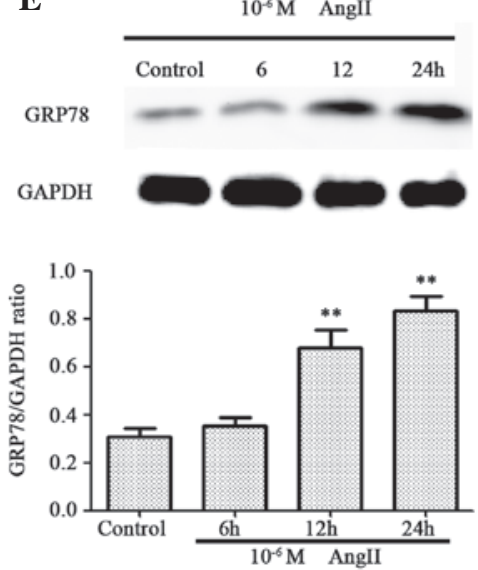

G

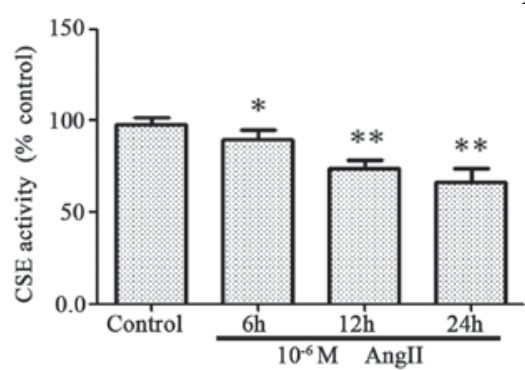

B

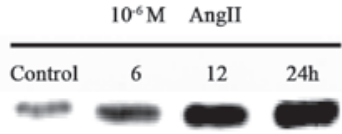

GAPDH

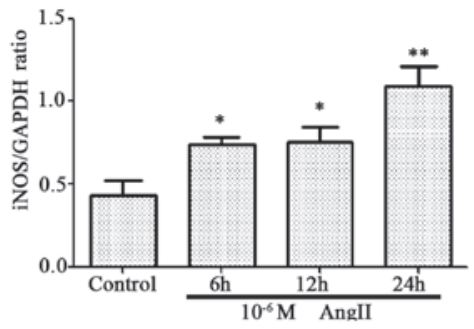

D

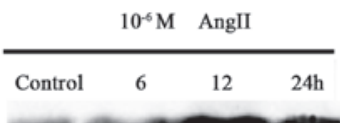

CHOP

GAPDH

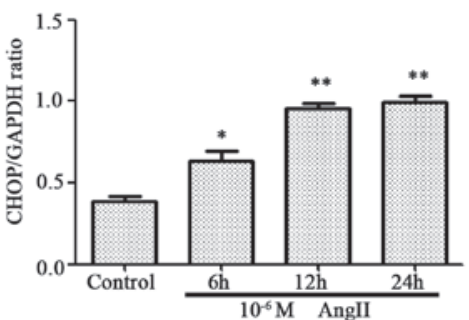

$\mathbf{F}$
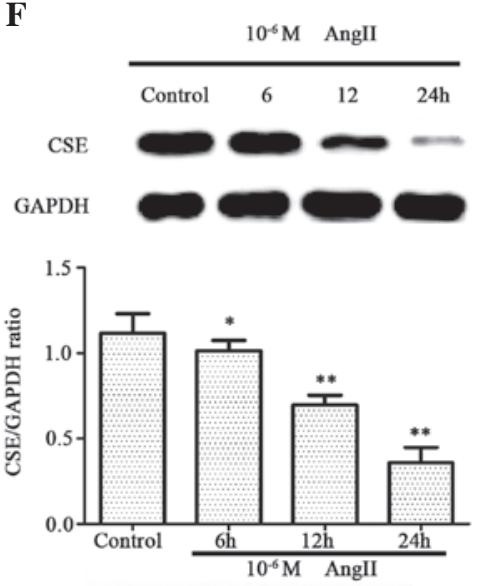

H

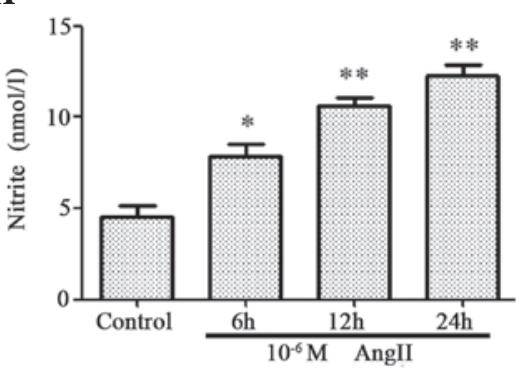

Figure 1. AngII induces cytotoxicity by triggering endoplasmic reticulum stress and inducing the expression of nuclear factor- $\mathrm{KB}$ and ET-1 in HUVECs. HUVECs were exposed to $10^{-6} \mathrm{M}$ AngII for 6, 12 or 24 h. Protein expression levels of (A) ET-1, (B) iNOS, (C) p-p65, (D) CHOP, (E) GRP78 and (F) CSE were assessed by western blot analysis. (G) CSE activity was assessed by methylene blue spectrophotometry. (H) Nitrite, a marker of nitric oxide production, was detected in culture supernatants using a Nitrite Detection kit. Data are presented as the mean \pm standard error of the mean ( $\mathrm{n}=3$ ). ${ }^{*} \mathrm{P}<0.05$ and ${ }^{* *} \mathrm{P}<0.01$ vs. control group. AngII, angiotensin II; ET-1, endothelin-1; HUVECs, human umbilical vein endothelial cells; iNOS, inducible nitric oxide synthase; p-p65, phosphorylated p65; T-p65, total p65; CHOP, CCAAT-enhancer-binding protein homologous protein; GRP78, glucose-regulated protein 78; CSE, cystathionine- $\gamma$-lyase; GAPDH, glyceraldehyde 3-phosphate dehydrogenase. 

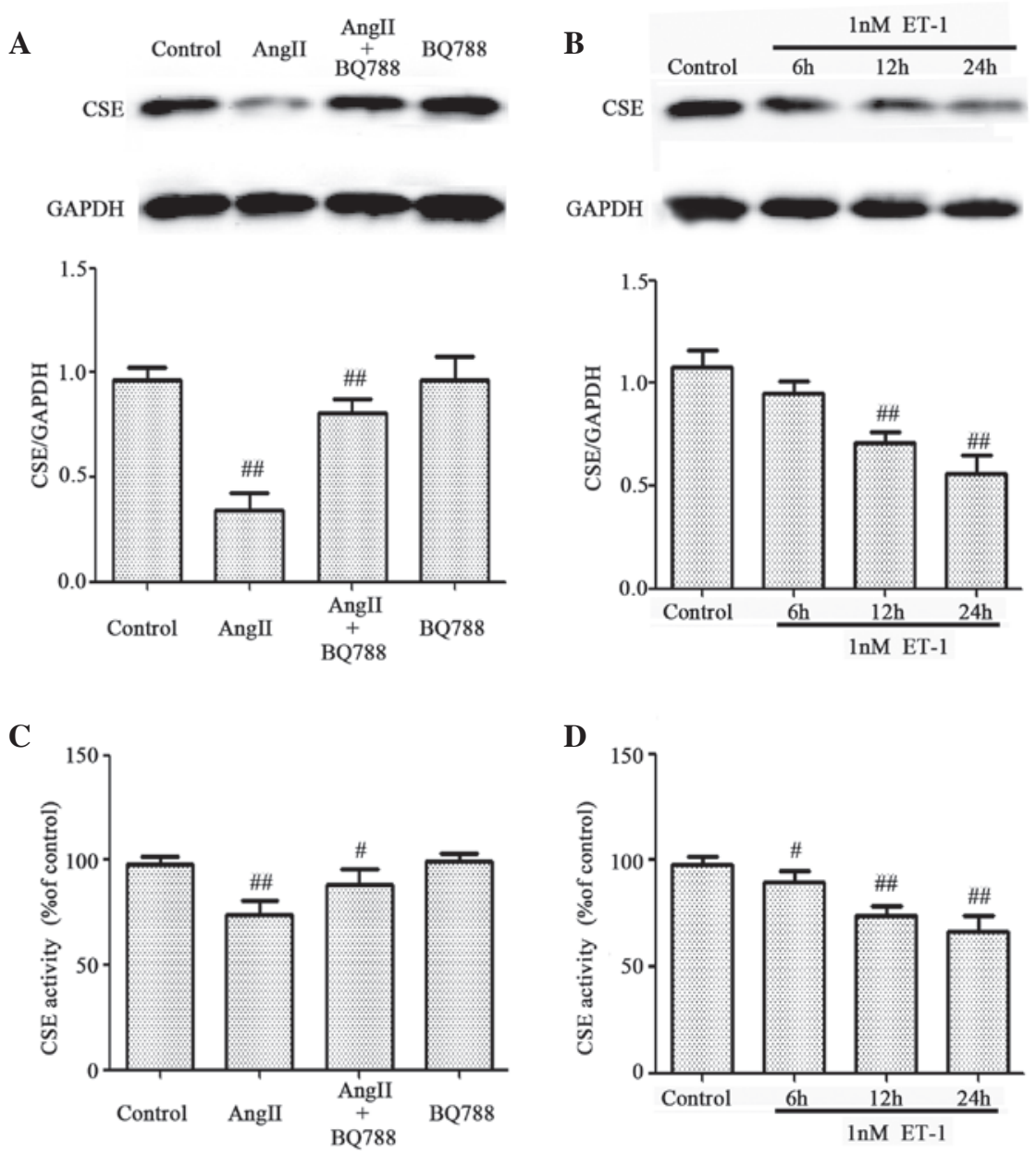

Figure 2. Role of ET-1 in the AngII-induced inhibition of CSE expression and activity. HUVECs were treated with $10^{-6} \mathrm{M}$ AngII for $24 \mathrm{~h}$ following pretreatment with $1 \mu \mathrm{M}$ BQ788 for $24 \mathrm{~h}$. (A) Protein expression levels of CSE were detected by western blotting. (B) CSE activity was assessed by methylene blue spectrophotometry. HUVECs were treated with $1 \mathrm{nM}$ ET-1 for 6, 12 or $24 \mathrm{~h}$. (C) Protein expression levels of CSE were detected by western blotting. (D) CSE activity was assessed by methylene blue spectrophotometry. Data are presented as the mean \pm standard error of the mean $(\mathrm{n}=3)$. ${ }^{\#} \mathrm{P}<0.05$ and ${ }^{\# \#} \mathrm{P}<0.01 \mathrm{vs}$. control group. ET-1, endothelin-1; AngII, angiotensin II; CSE, cystathionine- $\gamma$-lyase; HUVECs, human umbilical vein endothelial cells; GAPDH, glyceraldehyde 3-phosphate dehydrogenase.

Fig. 1, exposure of cells to $10^{-6} \mathrm{M}$ AngII for $24 \mathrm{~h}$ markedly enhanced the expression levels of p-p65. As presented in Fig. 3, pretreatment of cells with NaHS for $1 \mathrm{~h}$ prior to AngII exposure significantly abrogated AngII-induced cytotoxicity. Therefore, the potential involvement of the p-p65 signaling pathway in AngII-induced cytotoxicity was examined. HUVECs were pretreated with $100 \mu \mathrm{M}$ PDTC for $1 \mathrm{~h}$ prior to $10^{-6} \mathrm{M}$ AngII exposure for $24 \mathrm{~h}$. As presented in Fig. 5, pretreatment with PDTC had a similar cytoprotective effect to NaHS on AngII-induced overexpression of GRP78 (Fig. 5A), CHOP (Fig. 5B), iNOS (Fig. 5C) and nitrite (Fig. 5D), and AngII-induced decrease in cell viability (Fig. 5E), suggesting involvement of p-p65 activation in AngII-induced cytotoxicity in HUVECs. NaHS or PDTC treatment alone had no effect.

Exogenous $\mathrm{H}_{2} \mathrm{~S}$ and $\mathrm{NF}-\kappa \mathrm{B}$ inhibitor reduce AngII-induced apoptosis in HUVECs. The effects of NaHS and PDTC on AngII-induced apoptosis were investigated. As presented in Fig. 6, HUVECs treated with $10^{-6} \mathrm{M}$ AngII for $24 \mathrm{~h}$ exhibited typical apoptotic characteristics, including chromatin condensation, shrinkage of nuclei, and the presence of apoptotic bodies, and increased Hoechst (Fig. 6A and B) and TUNEL
(Fig. 6C and D) staining. However, pretreatment of cells with $200 \mu \mathrm{M}$ NaHS or $100 \mu \mathrm{M}$ PDTC for $1 \mathrm{~h}$ prior to AngII exposure markedly decreased the number of cells exhibiting nuclear condensation and fragmentation. NaHS or PDTC alone did not markedly alter cell morphology or the percentage of apoptotic HUVECs. In addition, western blot analysis (Fig. 7A and B) revealed that exposure of cells to $10^{-6} \mathrm{M}$ AngII for $24 \mathrm{~h}$ significantly upregulated the expression of cleaved caspase-12, which is considered to be one of the primary effectors of apoptosis (21); this effect was significantly abrogated by the pretreatment of cells with NaHS or PDTC for $1 \mathrm{~h}$. NaHS or PDTC alone did not affect the basal expression level of cleaved caspase-12 in HUVECs. These findings suggest that exogenous $\mathrm{H}_{2} \mathrm{~S}$ protects HUVECs against AngII-induced apoptosis, and that the NF- $\mathrm{kB}$ signaling pathway contributes to the AngII-induced apoptosis of HUVECs.

Exogenous $\mathrm{H}_{2} \mathrm{~S}$ and an ET-1 inhibitor attenuate the phosphorylation of p65 induced by AngII in HUVECs. It has previously been demonstrated that exogenous $\mathrm{H}_{2} \mathrm{~S}$ suppresses p-p65 in HUVECs (24), whereas AngII and ET-1 induce activation of p-p65 $(18,32)$. Since it has been demonstrated 

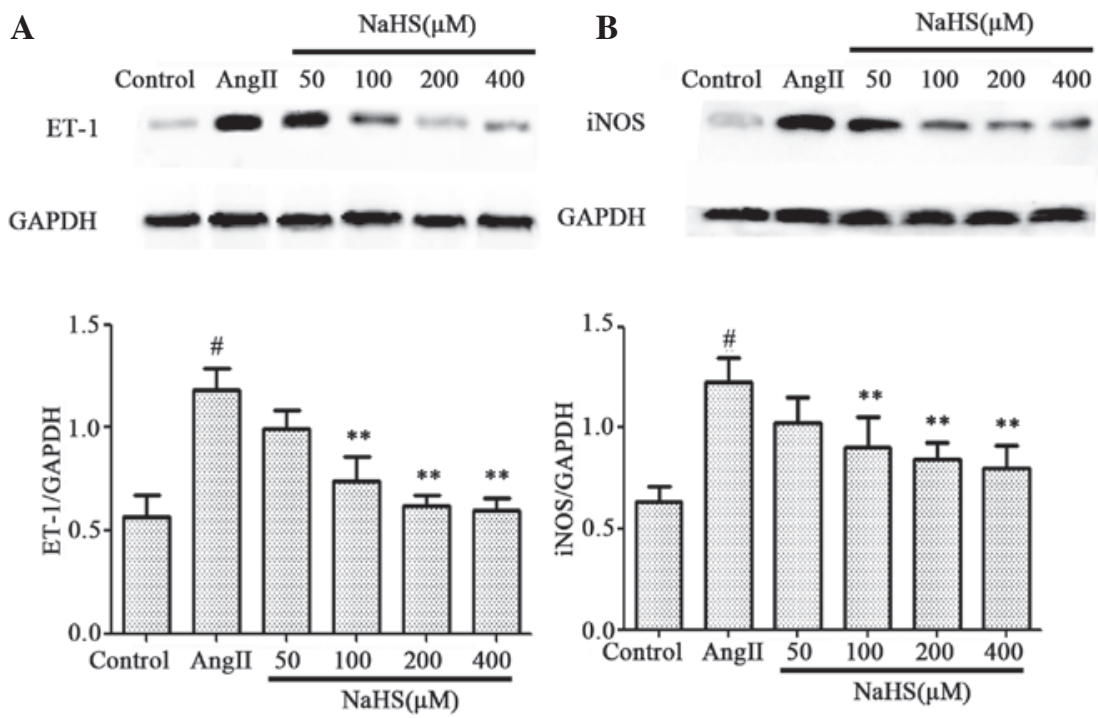

C

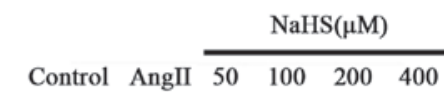

D

$\operatorname{NaHS}(\mu \mathrm{M})$

Control AngII $\begin{array}{rrrr}50 & 100 & 200 & 400\end{array}$

GRP78

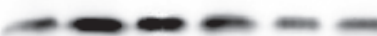

CHOP

GAPDH

GAPDH
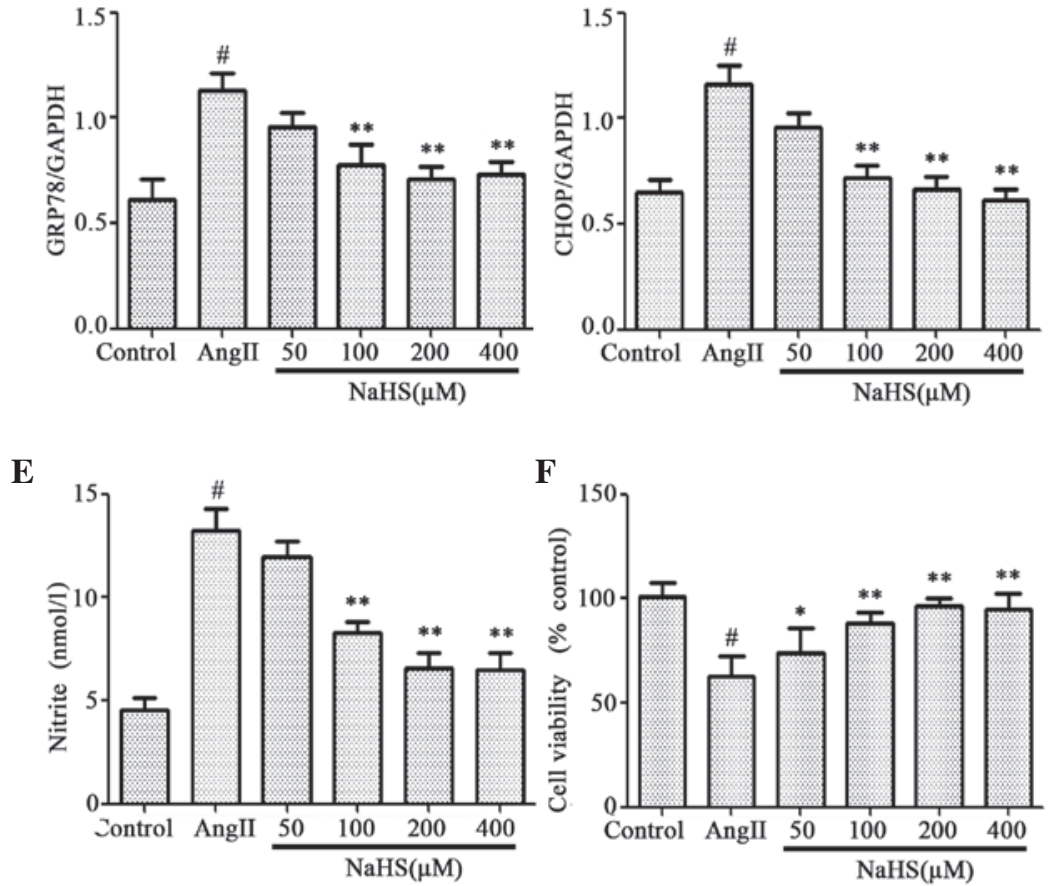

Figure 3. Effects of NaHS pretreatment on AngII-treated HUVECs. HUVECs were treated with $10^{-6} \mathrm{M}$ AngII for $24 \mathrm{~h}$ following pretreatment with NaHS at concentrations from 50 to $400 \mu \mathrm{M}$ for $1 \mathrm{~h}$. Protein expression levels of (A) ET-1, (B) iNOS, (C) GRP78 and (D) CHOP were assessed by western blot analysis. (E) Nitrite was detected in the culture supernatant using a Nitrite Detection kit. (F) Cell viability was measured using the Cell Counting kit-8 assay. Data are presented as the mean \pm standard error of the mean $(n=3)$. ${ }^{*} \mathrm{P}<0.05$ and ${ }^{* *} \mathrm{P}<0.01$ vs. AngII group; ${ }^{*} \mathrm{P}<0.01$ vs. control group. NaHS, sodium hydrosulfide; AngII, angiotensin II; HUVECs, human umbilical vein endothelial cells; ET-1, endothelin-1; iNOS, inducible nitric oxide synthase; GRP78, glucose-regulated protein 78; CHOP, CCAAT-enhancer-binding protein homologous protein; GAPDH, glyceraldehyde 3-phosphate dehydrogenase.

that p-p65-mediated endothelial cell insult contributes to ET-1-induced cytotoxicity (20), it was hypothesized that exogenous $\mathrm{H}_{2} \mathrm{~S}$ may inhibit activation of the ET-1/NF- $\mathrm{KB}$ signaling pathway during AngII-induced cytotoxicity in HUVECs. The effects of $\mathrm{H}_{2} \mathrm{~S}$ and an ET-1 inhibitor on the AngII-induced overexpression of p-p65 were therefore investigated. As 

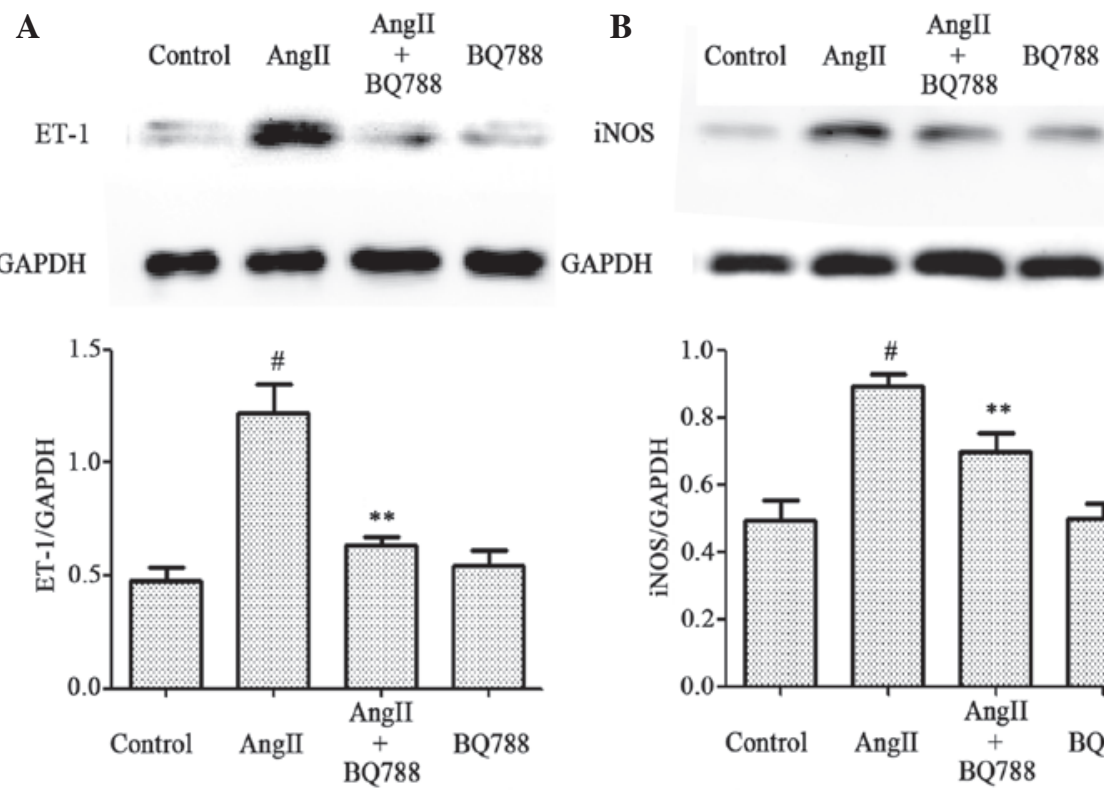

GAPDH
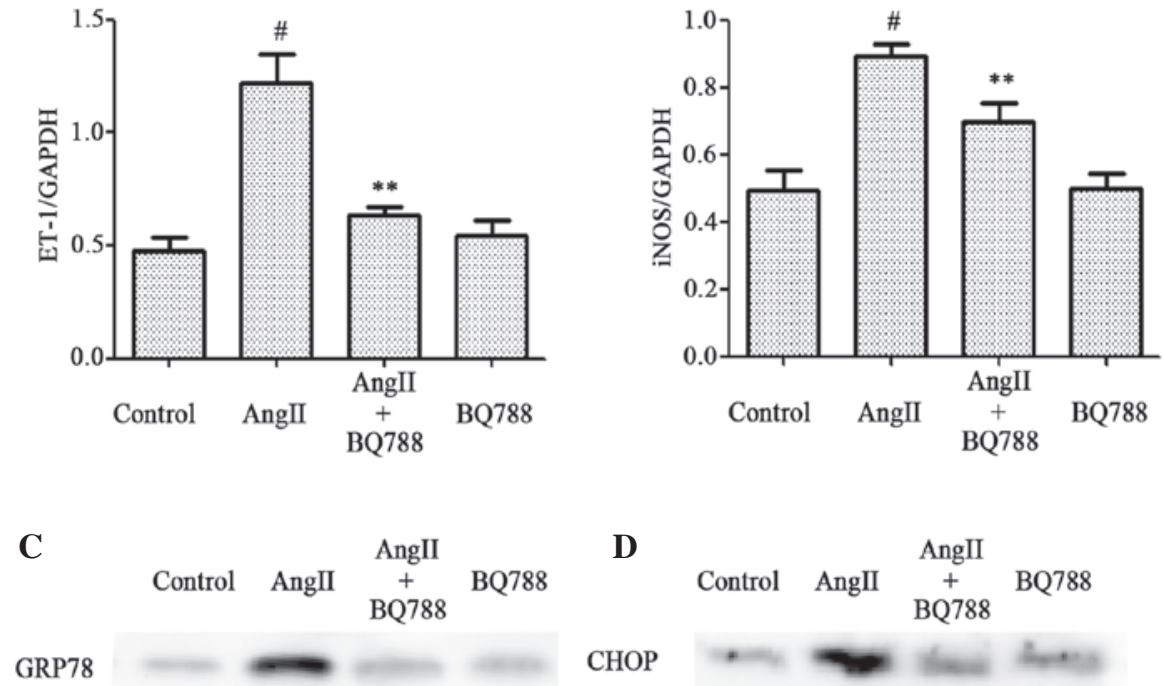

D

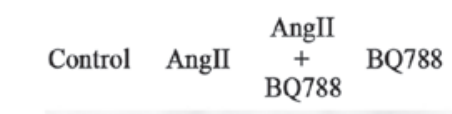

CHOP

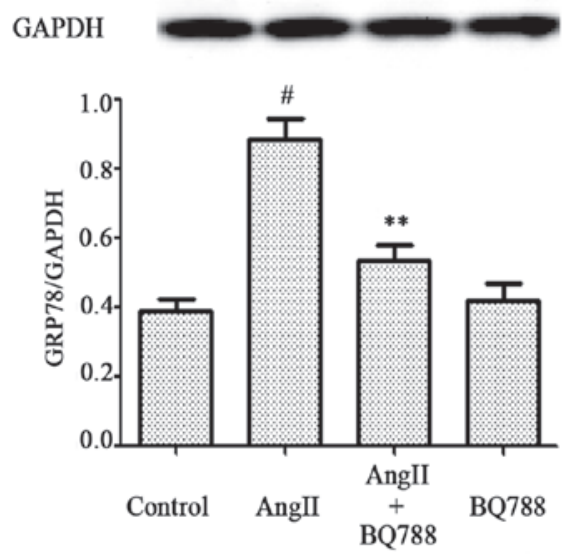

GAPDH
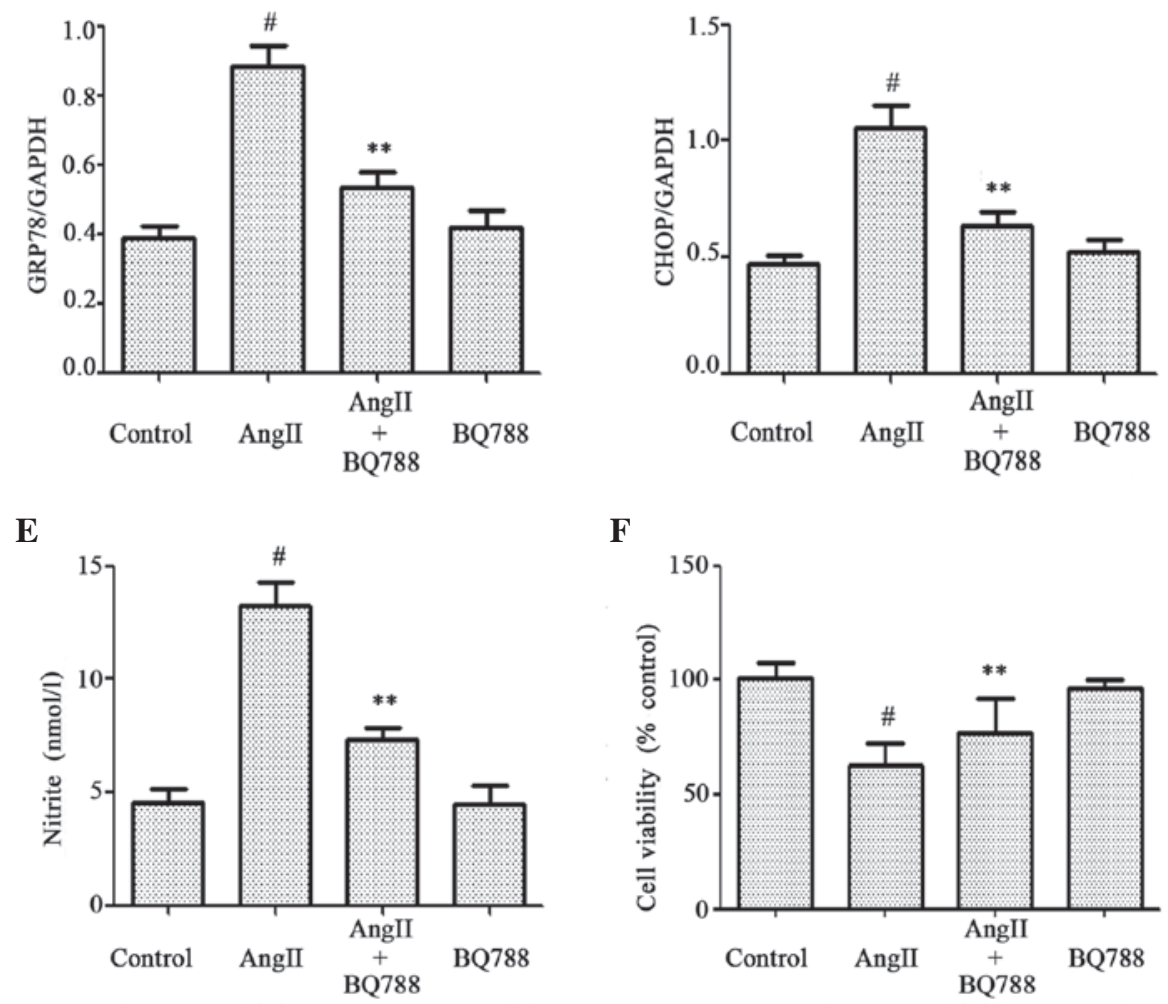

Figure 4. Effects of ET-1 inhibitor pretreatment on AngII-treated HUVECs. HUVECs were treated with $10^{-6} \mathrm{M}$ AngII for 24 h following pretreatment with $1 \mu \mathrm{M}$ BQ788 for $1 \mathrm{~h}$. Protein expression levels of (A) ET-1, (B) iNOS, (C) GRP78 and (D) CHOP were assessed by western blot analysis. (E) Nitrite was detected in the culture supernatant using a Nitrite Detection kit. (F) Cell viability was measured using the Cell Counting kit-8 assay. Data are presented as the mean \pm standard error of the mean $(n=3)$. ${ }^{* *} \mathrm{P}<0.01$ vs. AngII group; ${ }^{*} \mathrm{P}<0.01$ vs. control group. ET-1, endothelin-1; AngII, angiotensin II; HUVECs, human umbilical vein endothelial cells; iNOS, inducible nitric oxide synthase; GRP78, glucose-regulated protein 78; CHOP, CCAAT-enhancer-binding protein homologous protein; GAPDH, glyceraldehyde 3-phosphate dehydrogenase. 
A

$\mathbf{B}$

GRP78

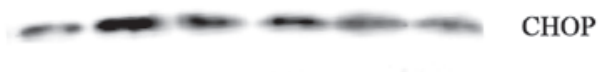

GAPDH

GAPDH

$\begin{array}{lllllll}\text { AngII } & - & + & + & + & - & - \\ \text { NaHS } & - & - & + & - & + & - \\ \text { PDTC } & - & - & - & + & - & +\end{array}$

AngII $-+++\quad+-$

NaHS

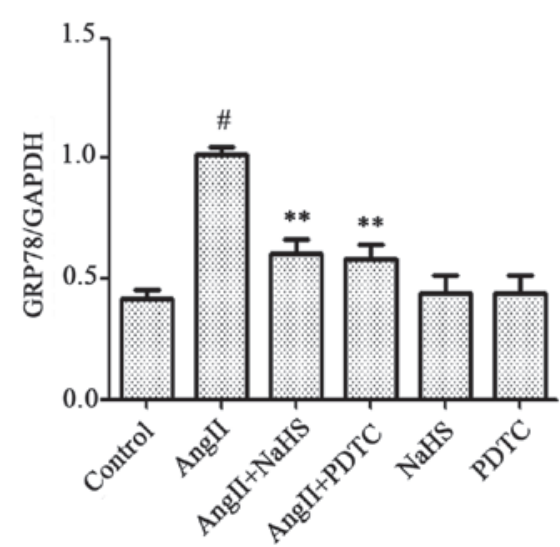

PDTC

C

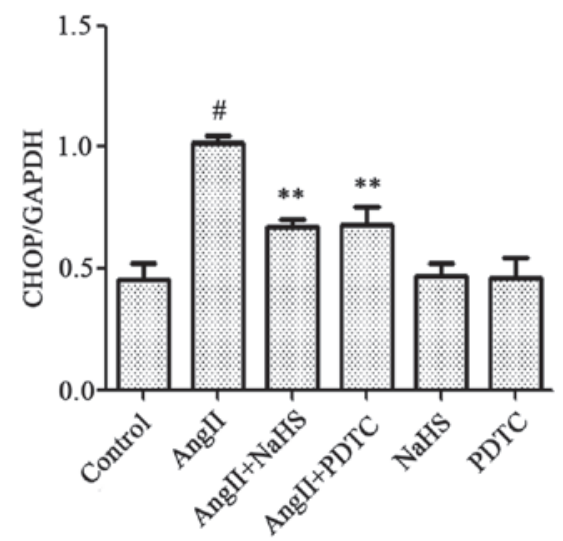

D
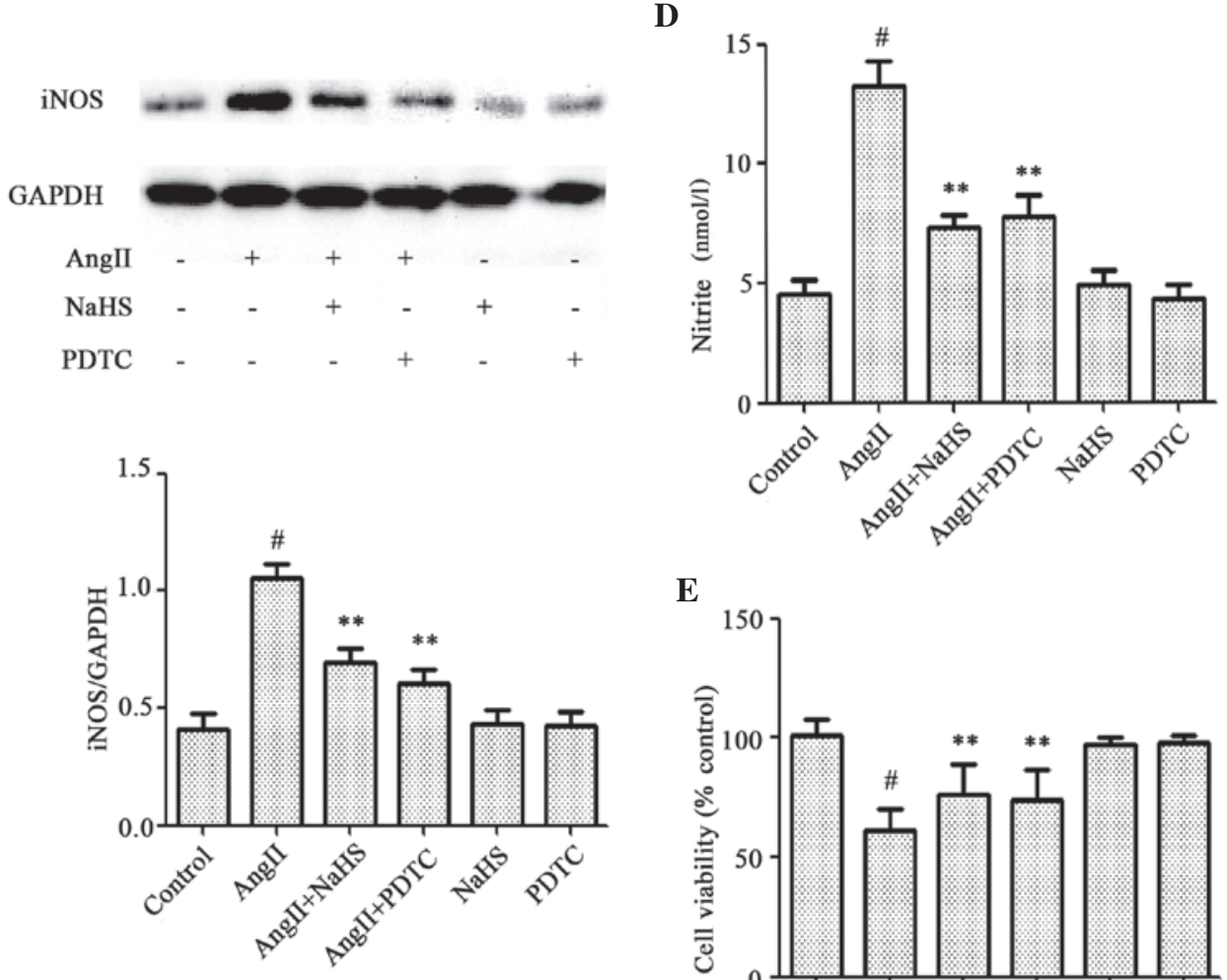

E

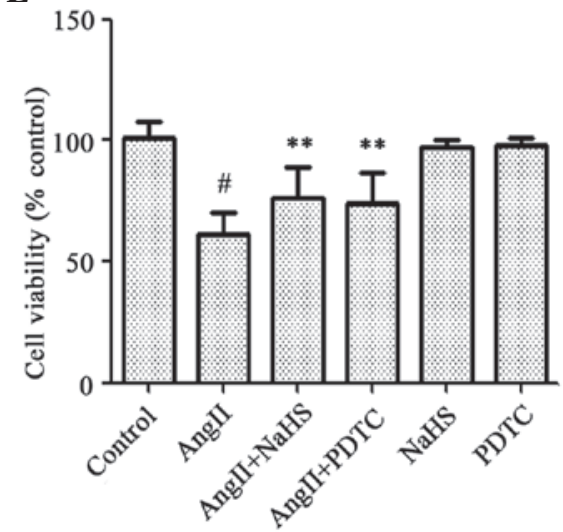

Figure 5. Exogenous $\mathrm{H}_{2} \mathrm{~S}$ and a nuclear factor- $\mathrm{BB}$ inhibitor attenuate AngII-induced cytotoxicity in HUVECs. HUVECs were treated with $10^{-6} \mathrm{M}$ AngII for $24 \mathrm{~h}$ following pretreatment with $200 \mu \mathrm{M}$ NaHS or $100 \mu \mathrm{M}$ PDTC for $1 \mathrm{~h}$ prior to AngII exposure. Protein expression levels of (A) GRP78, (B) CHOP and (C) iNOS were assessed by western blot analysis. (D) Nitrite was detected in the culture supernatant using a Nitrite Detection kit. (E) Cell viability was measured using the Cell Counting kit-8 assay. Data are presented as the mean \pm standard error of the mean $(\mathrm{n}=3) .{ }^{* *} \mathrm{P}<0.01$ vs. the AngII-treated group; ${ }^{*} \mathrm{P}<0.01$ vs. the control group. $\mathrm{H}_{2} \mathrm{~S}$, hydrogen sulfide; AngII, angiotensin II; HUVECs, human umbilical vein endothelial cells; NaHS, sodium hydrosulfide; PDTC, pyrrolidinedithiocarbamic acid; GRP78, glucose-regulated protein 78; CHOP, CCAAT-enhancer-binding protein homologous protein; iNOS, inducible nitric oxide synthase; GAPDH, glyceraldehyde 3-phosphate dehydrogenase. 


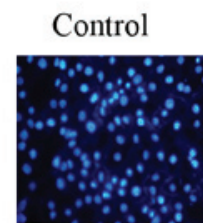

AngII+PDTC
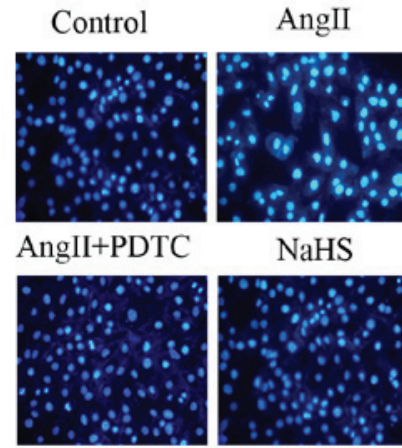

$\mathrm{NaHS}$

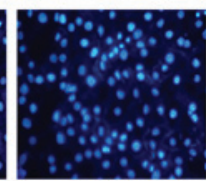

PDTC
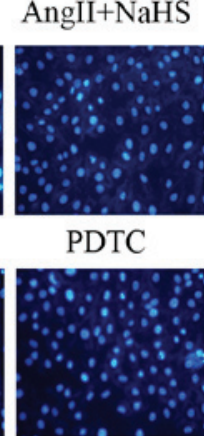

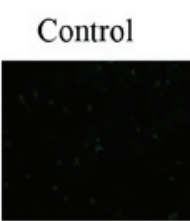

AngII+PDTC

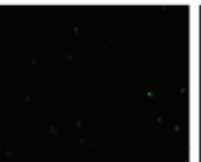

AngII

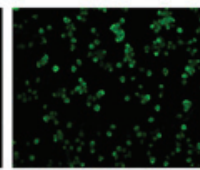

$\mathrm{NaHS}$

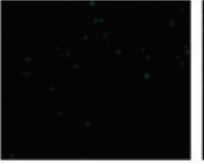

AngII+NaHS

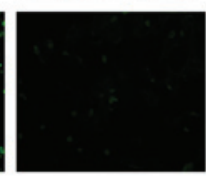

PDTC
B

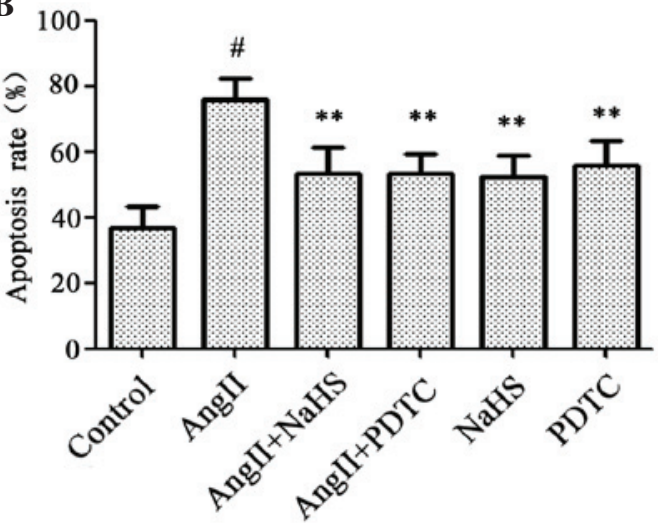

D

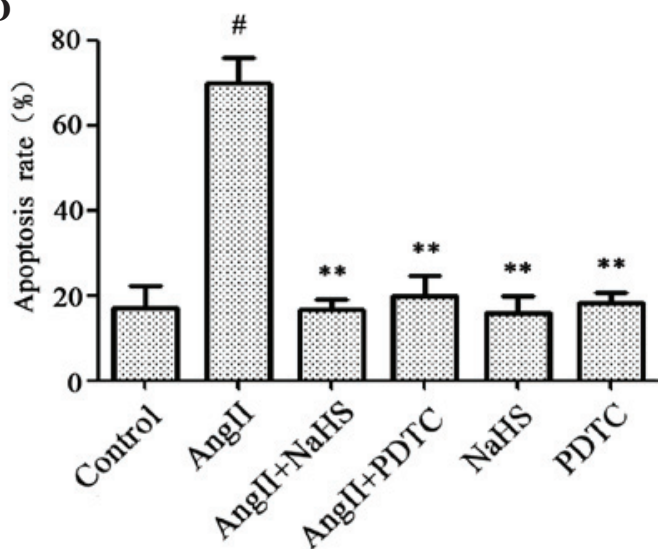

Figure 6. Exogenous $\mathrm{H}_{2} \mathrm{~S}$ and a nuclear factor- $\mathrm{kB}$ inhibitor reduce AngII-induced apoptosis in HUVECs. HUVECs were treated with $10^{-6} \mathrm{M}$ AngII for $24 \mathrm{~h}$ following pretreatment with $200 \mu \mathrm{M}$ NaHS or $100 \mu \mathrm{M}$ PDTC for $1 \mathrm{~h}$ prior to AngII exposure. (A) Cells were stained with Hoechst 33258 (magnification, $\mathrm{x} 200$ ) and (B) the apoptosis rate was calculated. (C) Cells were stained with TUNEL (magnification, x200) and (D) the apoptosis rate was calculated. Data are presented as the mean \pm standard error of the mean $(n=3)$. ${ }^{* *} \mathrm{P}<0.01$ vs. AngII-treated group; ${ }^{\prime \prime} \mathrm{P}<0.01$ vs. control group. $\mathrm{H}_{2} \mathrm{~S}$, hydrogen sulfide; AngII, angiotensin II; HUVECs, human umbilical vein endothelial cells; NaHS, sodium hydrosulfide; PDTC, pyrrolidinedithiocarbamic acid; TUNEL, terminal deoxynucleotidyl transferase mediated dUTP nick end labeling.

presented in Fig. 8, following treatment with $10^{-6} \mathrm{M}$ AngII for 24 h, HUVECs significantly overexpressed p-p65. Notably, this effect was attenuated by pretreatment with $200 \mu \mathrm{M}$ NaHS for $1 \mathrm{~h}$ or $1 \mu \mathrm{M}$ BQ788 for $1 \mathrm{~h}$ prior to AngII exposure. These data suggest that exogenous $\mathrm{H}_{2} \mathrm{~S}$ and ET-1 inhibition protect HUVECs against AngII-induced cytotoxicity via the ET-1/NF- $\kappa$ B signaling pathway.

\section{Discussion}

RAS, particularly AngII, has been demonstrated to be crucial for the progression of AS (33); however, the underlying mechanisms remain to be fully elucidated. Evidence suggests that ER stress and ED are key contributors to AngII-induced cytotoxicity $(15,34)$. Consistent with previous studies $(15,34,35)$, the present study revealed that AngII markedly induced HUVEC injury, including a decrease in cell viability, and increases in NO production, protein expression levels of iNOS, ET-1, GRP78 and CHOP, as well as phosphorylation of p65.

Previous studies have demonstrated that AngII induces numerous inflammatory mediators, including ET-1 (36-38), which is implicated in the progression of endothelial cell injury (39-41). Therefore, the present study confirmed that the activation of ET-1 is crucial for AngII-induced cytotoxicity. The findings of the present study revealed that pretreatment of HUVECs with BQ788, a specific inhibitor of ET-1, significantly abrogated the inhibition of CSE expression and activity levels induced by AngII. Furthermore, administration of exogenous ET-1 imitated the inhibitory effect of AngII on the expression and activity of CSE in HUVECs. Therefore, ET-1 may affect the function of endothelial cells by inhibiting the expression and activity of CSE.

Features of $\mathrm{H}_{2} \mathrm{~S}$, an active gasotransmitter, include low molecular weight, continuous production, quick diffusion and extensive biological effects (42). It has previously been demonstrated that $\mathrm{H}_{2} \mathrm{~S}$ is cytoprotective, and its generation in vessels was decreased upon RAS activation (26), which has been revealed to be an important factor in the development of AS (43). The majority of studies using $\mathrm{H}_{2} \mathrm{~S}$ donors, including NaHS and GYY4137 have demonstrated that exogenous $\mathrm{H}_{2} \mathrm{~S}$ attenuates a multitude of pathophysiological processes, such as vascular endothelium dysfunction and smooth muscle cell proliferation (44-46). The present study demonstrated that AngII-induced cytotoxicity significantly suppressed the expression and activity of CSE in HUVECs; therefore, it was hypothesized that supplementation of $\mathrm{H}_{2} \mathrm{~S}$ may protect 
A

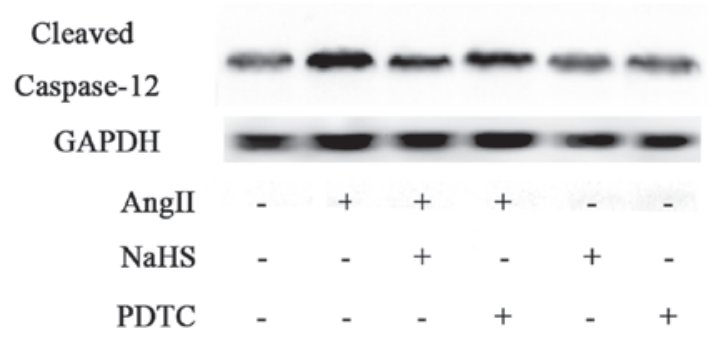

B

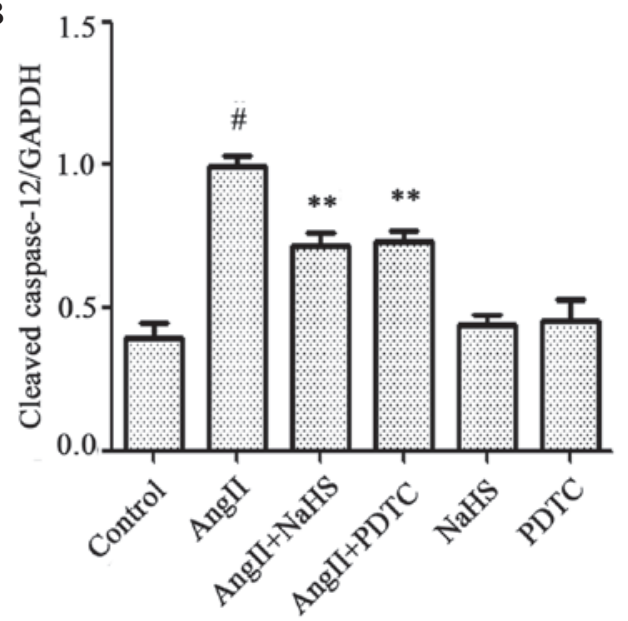

Figure 7. Exogenous $\mathrm{H}_{2} \mathrm{~S}$ and a nuclear factor- $\kappa \mathrm{B}$ inhibitor suppress the AngII-induced increase in the expression level of cleaved caspase-12 in HUVECs. HUVECs were treated with $10^{-6} \mathrm{M}$ AngII for $24 \mathrm{~h}$ following pretreatment with $200 \mu \mathrm{M}$ NaHS or $100 \mu \mathrm{M}$ PDTC for $1 \mathrm{~h}$ prior to AngII exposure. (A) Protein expression levels of cleaved caspase-12 were assessed by western blotting. (B) Quantification of western blotting. Data are presented as the mean \pm standard error of the mean $(n=3) .{ }^{* *} \mathrm{P}<0.01$ vs. AngII-treated group; ${ }^{\#} \mathrm{P}<0.01$ vs. control group. $\mathrm{H}_{2} \mathrm{~S}$, hydrogen sulfide; AngII, angiotensin II; HUVECs, human umbilical vein endothelial cells; NaHS, sodium hydrosulfide; PDTC, pyrrolidinedithiocarbamic acid; GAPDH, glyceraldehyde 3-phosphate dehydrogenase.

HUVECs against AngII-induced ED. This hypothesis was supported by the results of the present study. When HUVECs were pretreated with NaHS for $1 \mathrm{~h}$ prior to AngII exposure for $24 \mathrm{~h}$, AngII-stimulated cytotoxicity was markedly abrogated, evidenced by increased cell viability. These data are consistent with a previous study, which demonstrated that NaHS markedly improves ED induced by AngII (28). Since $\mathrm{H}_{2} \mathrm{~S}$ is known to be protective of endothelial cells, the present study pretreated HUVECs with NaHS for $1 \mathrm{~h}$ prior to incubation with AngII for $24 \mathrm{~h}$. Pretreated cells had almost undetectable levels of CHOP, GRP78, iNOS and nitrite, and significantly improved cell viability. These results suggest that $\mathrm{H}_{2} \mathrm{~S}$ exerts protective effects against AngII-induced cytotoxicity in HUVECs. In addition, HUVECs pretreated with PDTC for $1 \mathrm{~h}$ prior to incubation with AngII for $24 \mathrm{~h}$ had almost undetectable levels of CHOP, GRP78, iNOS and nitrite, and significantly improved cell viability; mimicking the effects of NaHS.

A previous study revealed that the NF- $\kappa \mathrm{B}$ signaling pathway is involved in AngII-induced HUVEC dysfunction (18), and it is widely accepted that NF- $\mathrm{kB}$ is required for full induction of ET-1 (47). NF- $\mathrm{KB}$ is expressed in the majority of cell types and is crucial for transcription. The p65
A
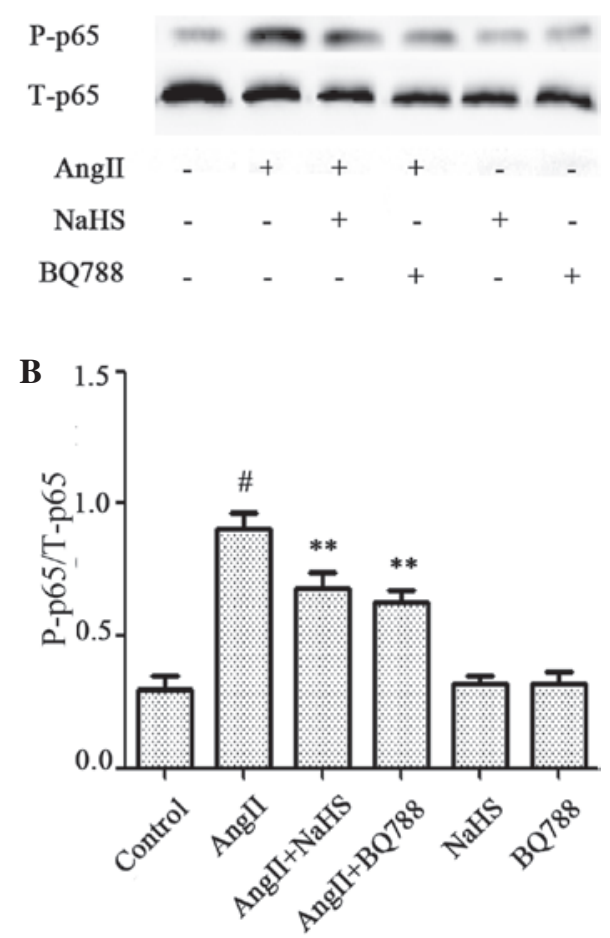

Figure 8. Exogenous $\mathrm{H}_{2} \mathrm{~S}$ and nuclear factor- $\kappa \mathrm{B}$ inhibitor ameliorate AngII-induced increase in the expression levels of p-p65 in HUVECs. HUVECs were treatecd with $10^{-6} \mathrm{M}$ AngII for $24 \mathrm{~h}$ following pretreatment with $200 \mu \mathrm{M}$ NaHS or $1 \mu \mathrm{M}$ BQ788 for $1 \mathrm{~h}$ prior to AngII exposure. (A) Protein expression levels of p-p65 and t-p65 were assessed by western blotting. (B) Quantification of western blotting. Data are presented as the mean \pm standard error of the mean $(\mathrm{n}=3)$. ${ }^{* *} \mathrm{P}<0.01$ vs. AngII-treated group; ${ }^{\#} \mathrm{P}<0.01$ vs. control group. $\mathrm{H}_{2} \mathrm{~S}$, hydrogen sulfide; AngII, angiotensin II; HUVECs, human umbilical vein endothelial cells; NaHS, sodium hydrosulfide; p-p65, phosphorylated p65; T-p65, total p65.

protein is the primary transcriptionally active component of $\mathrm{NF}-\kappa \mathrm{B}(48)$. It was hypothesized that NF- $\mathrm{B}$ is involved in the mechanism underlying $\mathrm{H}_{2} \mathrm{~S}$ suppression of AngII-stimulated cytotoxicity in HUVECs. Therefore, the present study examined the effects of $\mathrm{H}_{2} \mathrm{~S}$ on p-p65 protein expression levels in HUVECs exposed to AngII. P-p65 was significantly increased in HUVECs exposed to AngII. Conversely, pretreatment with $200 \mu \mathrm{M}$ NaHS or $1 \mu \mathrm{M}$ BQ788 for $1 \mathrm{~h}$ significantly decreased the p-p65 protein expression level in HUVECs exposed to AngII.

To investigate whether the protective effect of exogenous $\mathrm{H}_{2} \mathrm{~S}$ on AngII-stimulated cytotoxicity via the NF- $\mathrm{kB}$ signaling pathway in HUVECs is associated with its endothelial cell protective function, the effects of NaHS and PDTC on HUVEC apoptosis and caspase-12 cleavage induced by AngII were examined. NaHS and PDTC attenuated apoptosis in HUVECs, which is a key process in ED during the development of AS. Consistent with this, Qabazard et al (49) demonstrated that supplementation with GYY4137 markedly decreased oxidative stress-induced overexpression of CHOP, GRP78 and caspase-12 in endothelial cells. In addition, this study demonstrated that $\mathrm{p} 38$ mitogen-activated protein kinases (MAPK) demonstrated a key role in the regulation of AngII-induced ED (49). Therefore, p38 MAPK may be a good target for NaHS to intervene in AngII-induced ED. 
Qabazard et al (49) investigated whether the AngII-stimulated ET-1 generation is crucial for the regulation of p38 MAPK expression. In addition, Touyz et al (50) revealed that pretreatment with BQ788 $1 \mathrm{~h}$ prior to incubation with AngII for $24 \mathrm{~h}$ may inhibit expression of p-p38 MAPK induced by AngII. Since NaHS attenuated AngII-induced p-p38MAPK expression, this may provide, at least partially, the mechanism underlying the increased expression of ET-1 and AngII during the development of AS.

In conclusion, the present study, to the best of our knowledge, is the first to demonstrate that ET-1-mediated inhibition of CSE expression and activity is involved in AngII-induced cytotoxicity. $\mathrm{H}_{2} \mathrm{~S}$ supplementation may protect against AngII-stimulated ET-1 generation and subsequent cytotoxicity in HUVECs via the inhibition of $\mathrm{p}-\mathrm{NF}-\kappa \mathrm{B}$ expression. The findings of the present study suggested that exogenous $\mathrm{H}_{2} \mathrm{~S}$ may provide a potential novel therapeutic strategy for the prevention and treatment of AS.

\section{References}

1. Feinstein M, Ning H, Kang J, Bertoni A, Carnethon M and Lloyd-Jones DM: Racial differences in risks for first cardiovascular events and noncardiovascular death: The atherosclerosis risk in communities study, the cardiovascular health study, and the multi-ethnic study of atherosclerosis. Circulation 126: 50-59, 2012

2. Davignon J and Ganz P: Role of endothelial dysfunction in atherosclerosis. Circulation 109 (23 Suppl 1): III27-III32, 2004.

3. Loyer X, Potteaux S, Vion AC, Guérin CL, Boulkroun S, Rautou PE, Ramkhelawon B, Esposito B, Dalloz M, Paul JL, et al: Inhibition of microRNA-92a prevents endothelial dysfunction and atherosclerosis in mice. Circ Res 114: 434-443, 2014.

4. Barton M, Haudenschild CC, d'Uscio LV, Shaw S, Münter K and Luscher TF: Endothelin ETA receptor blockade restores NO-mediated endothelial function and inhibits atherosclerosis in apolipoprotein E-deficient mice. Proc Natl Acad Sci USA 95: 14367-14372, 1998.

5. Brunner F, Brás-Silva C, Cerdeira AS and Leite-Moreira AF: Cardiovascular endothelins: Essential regulators of cardiovascular homeostasis. Pharmacol Ther 111: 508-531, 2006.

6. Kamata K, Kanie N, Matsumoto $\mathrm{T}$ and Kobayashi T: Endothelin-1-induced impairment of endothelium-dependent relaxation in aortas isolated from controls and diabetic rats. J Cardiovasc Pharmacol 1 (44 Suppl): S186-S190, 2004.

7. Barton M, Traupe T and Haudenschild CC: Endothelin, hypercholesterolemia and atherosclerosis. Coron Artery Dis 14: 477-490, 2003.

8. Tummala PE, Chen XL, Sundell CL, Laursen JB, Hammes CP Alexander RW, Harrison DG and Medford RM: Angiotensin II induces vascular cell adhesion molecule-1 expression in rat vasculature: A potential link between the renin-angiotensin system and atherosclerosis. Circulation 100: 1223-1229, 1999.

9. Marampon F, Gravina GL, Scarsella L, Festuccia C, Lovat F, Ciccarelli C, Zani BM, Polidoro L, Grassi D, Desideri G, et al: Angiotensin-converting-enzyme inhibition counteracts angiotensin II-mediated endothelial cell dysfunction by modulating the p38/SirT1 axis. J Hypertens 31: 1972-1983, 2013.

10. Ayari H: Respective roles of cortisol, aldosterone and angiotensin II during pathophysiology of atherosclerosis. Ann Biol Clin (Paris) 71: 381-388, 2013 (In French).

11. Nishida Y, Takahashi Y, Susa N, Kanou N, Nakayama T and Asai S: Comparative effect of angiotensin II type I receptor blockers on serum uric acid in hypertensive patients with type 2 diabetes mellitus: A retrospective observational study. Cardiovasc Diabetol 12: 159, 2013.

12. Ocaranza MP, Michea L, Chiong M, Lagos CF, Lavandero S and Jalil JE: Recent insights and therapeutic perspectives of angiotensin-(1-9) in the cardiovascular system. Clin Sci (Lond) 127: 549-557, 2014.

13. Yang HY, Bian YF, Zhang HP, Gao F, Xiao CS, Liang B, Li J, Zhang NN and Yang ZM: Angiotensin-(1-7) treatment ameliorates angiotensin II-induced apoptosis of human umbilical vein endothelial cells. Clin Exp Pharmacol Physiol 39: 1004-1010, 2012.
14. Ron D and Walter P: Signal integration in the endoplasmic reticulum unfolded protein response. Nat Rev Mol Cell Biol 8: 519-529, 2007.

15. Uhal BD, Nguyen H, Dang M, Gopallawa I, Jiang J, Dang V, Ono S and Morimoto K: Abrogation of ER stress-induced apoptosis of alveolar epithelial cells by angiotensin 1-7. Am J Physiol Lung Cell Mol Physiol 305: L33-L41, 2013.

16. Chistiakov DA, Sobenin IA, Orekhov AN and Bobryshev YV: Role of endoplasmic reticulum stress in atherosclerosis and diabetic macrovascular complications. Biomed Res Int 2014: 610140, 2014.

17. Chaudhari N, Talwar P, Parimisetty A, Lefebvre d'Hellencourt C and Ravanan P: A molecular web: Endoplasmic reticulum stress, inflammation, and oxidative stress. Front Cell Neurosci 8: 213, 2014.

18. Guo RW, Yang LX, Li MQ, Liu B and Wang XM: Angiotensin II induces NF-kappa B activation in HUVEC via the p38MAPK pathway. Peptides 27: 3269-3275, 2006.

19. Pushpakumar SB, Kundu S and Sen U: Endothelial dysfunction: The link between homocysteine and hydrogen sulfide. Curr Med Chem 21: 3662-3672, 2014

20. Łowicka $E$ and Beltowski J: Hydrogen sulfide $\left(\mathrm{H}_{2} \mathrm{~S}\right)$-the third gas of interest for pharmacologists. Pharmacol Rep 59: 4-24, 2007.

21. Yang G, Wu L, Jiang B, Yang W, Qi J, Cao K, Meng Q, Mustafa AK, $\mathrm{Mu} \mathrm{W}$, Zhang $\mathrm{S}$, et al: $\mathrm{H}_{2} \mathrm{~S}$ as a physiologic vasorelaxant: Hypertension in mice with deletion of cystathionine gamma-lyase. Science 322: 587-590, 2008.

22. Suo R, Zhao ZZ, Tang ZH, Ren Z, Liu X, Liu LS, Wang Z, Tang CK, Wei DH and Jiang ZS: Hydrogen sulfide prevents $\mathrm{H}_{2} \mathrm{O}_{2}$-induced senescence in human umbilical vein endothelial cells through SIRT1 activation. Mol Med Rep 7: 1865-1870, 2013.

23. Ng DS, Peh MT, Anwar AB, Mohammed Atan MSB, Tsai C-Yi, Kumar SD and Moore PK: P27 Changes in the hydrogen sulfide $\left(\mathrm{H}_{2} \mathrm{~S}\right)$ system arising from administration of high fat diet. Nitric Oxide 31 (Suppl 2): S46-S47, 2013.

24. Pan LL, Liu XH, Gong QH, Wu D and Zhu YZ: Hydrogen sulfide attenuated tumor necrosis factor- $\alpha$-induced inflammatory signaling and dysfunction in vascular endothelial cells. PLoS One 6: e19766, 2011.

25. Mani S, Untereiner A, Wu L and Wang R: Hydrogen sulfide and the pathogenesis of atherosclerosis. Antioxid Redox Signal 20: 805-817, 2014.

26. Xue H, Yuan P, Ni J, Li C, Shao D, Liu J, Shen Y, Wang Z, Zhou L, Zhang W, et al: $\mathrm{H}(2) \mathrm{S}$ inhibits hyperglycemia-induced intrarenal renin-angiotensin system activation via attenuation of reactive oxygen species generation. PLoS One 8: e74366, 2013.

27. Lin YJ, Kwok CF, Juan CC, Hsu YP, Shih KC, Chen CC and Ho LT: Angiotensin II enhances endothelin-1-induced vasoconstriction through upregulating endothelin type A receptor. Biochem Biophys Res Commun 451: 263-269, 2014.

28. Al-Magableh MR, Kemp-Harper BK and Hart JL: Hydrogen sulfide treatment reduces blood pressure and oxidative stress in angiotensin II-induced hypertensive mice. Hypertens Res 38: 13-20, 2015.

29. Kossmann S, Hu H, Steven S, Schönfelder T, Fraccarollo D, Mikhed Y, Brähler M, Knorr M, Brandt M, Karbach SH, et al: Inflammatory monocytes determine endothelial nitric oxide synthase uncoupling and nitro-oxidative stress induced by angiotensin II. J Biol Chem 289: 27540-27550, 2014.

30. Miyata K, Satou R, Shao W, Prieto MC, Urushihara M, Kobori H and Navar LG: ROCK/NF- $\mathrm{BB}$ axis-dependent augmentation of angiotensinogen by angiotensin II in primary-cultured preglomerular vascular smooth muscle cells. Am J Physiol Renal Physiol 306: F608-F618, 2014.

31. Adiarto S, Heiden S, Vignon-Zellweger N, Nakayama K, Yagi K, Yanagisawa M and Emoto N: ET-1 from endothelial cells is required for complete angiotensin II-induced cardiac fibrosis and hypertrophy. Life Sci 91: 651-657, 2012.

32. Browatzki M, Schmidt J, Kübler W and Kranzhöfer R: Endothelin-1 induces interleukin-6 release via activation of the transcriptio $n$ factor NF-kappaB in human vascular smooth muscle cells. Basic Res Cardiol 95: 98-105, 2000.

33. Chen X, Rateri DL, Howatt DA, Balakrishnan A, Moorleghen JJ, Morris AJ, Charnigo R, Cassis LA and Daugherty A: Amlodipine reduces AngII-induced aortic aneurysms and atherosclerosis in hypercholesterolemic mice. PLoS One 8: e81743, 2013.

34. Murdoch CE, Chaubey S, Zeng L, Yu B, Ivetic A, Walker SJ, Vanhoutte D, Heymans S, Grieve DJ, Cave AC, et al: Endothelial NADPH oxidase-2 promotes interstitial cardiac fibrosis and diastolic dysfunction through proinflammatory effects and endothelial-mesenchymal transition. J Am Coll Cardiol 63: 2734-2741, 2014. 
35. Wei LH, Huang XR, Zhang Y, Li YQ, Chen HY, Heuchel R, Yan BP, Yu CM and Lan HY: Deficiency of Smad7 enhances cardiac remodeling induced by angiotensin II infusion in a mouse model of hypertension. PLoS One 8: e70195, 2013.

36. Lin CC, Hsieh HL, Chi PL, Yang CC, Hsiao LD and Yang CM: Upregulation of $\mathrm{COX}-2 / \mathrm{PGE} 2$ by ET-1 mediated through Ca2+-dependent signals in mouse brain microvascular endothelial cells. Mol Neurobiol 49: 1256-1269, 2014.

37. Shiraki A, Oyama J, Komoda H, Asaka M, Komatsu A, Sakuma M, Kodama K, Sakamoto Y, Kotooka N, Hirase T and Node K: The glucagon-like peptide 1 analog liraglutide reduces TNF- $\alpha$-induced oxidative stress and inflammation in endothelial cells. Atherosclerosis 221: 375-382, 2012.

38. Lee W, Ku SK and Bae JS: Factor Xa inhibits HMGB1-induced septic responses in human umbilical vein endothelial cells and in mice. Thromb Haemost 112: 757-769, 2014.

39. Schrader LI, Kinzenbaw DA, Johnson AW, Faraci FM and Didion SP: IL-6 deficiency protects against angiotensin II induced endothelial dysfunction and hypertrophy. Arterioscler Thromb Vasc Biol 27: 2576-2581, 2007.

40. Rojas E, Rodríguez-Molina D, Bolli P, Israili ZH, Faría J, Fidilio E, Bermúdez $\mathrm{V}$ and Velasco M: The role of adiponectin in endothelial dysfunction and hypertension. Curr Hypertens Rep 16: 463, 2014.

41. Lamarca B: Endothelial dysfunction. An important mediator in the pathophysiology of hypertension during pre-eclampsia. Minerva Ginecol 64: 309-320, 2012.

42. Du J, Huang Y, Yan H, Zhang Q, Zhao M, Zhu M, Liu J, Chen SX, $\mathrm{Bu}$ D, Tang $\mathrm{C}$ and Jin $\mathrm{H}$ : Hydrogen sulfide suppresses oxidized low-density lipoprotein (ox-LDL)-stimulated monocyte chemoattractant protein 1 generation from macrophages via the nuclear factor kappaB (NF-кB) pathway. J Biol Chem 289: 9741-9753, 2014.
43. Sata $M$ and Fukuda D: Crucial role of renin-angiotensin system in the pathogenesis of atherosclerosis. J Med Invest 57: $12-25,2010$.

44. Lynn EG and Austin RC: Hydrogen sulfide in the pathogenesis of atherosclerosis and its therapeutic potential. Expert Rey Clin Pharmacol 4: 97-108, 2011.

45. Liu Z, Han Y, Li L, Lu H, Meng G, Li X, Shirhan M, Peh MT, Xie L, Zhou S, et al: The hydrogen sulfide donor, GYY4137, exhibits anti-atherosclerotic activity in high fat fed apolipoprotein E(-/-) mice. Br J Pharmacol 169: 1795-1809, 2013.

46. Meng G, Zhu J, Xiao Y, Huang Z, Zhang Y, Tang X, Xie L, Chen Y, Shao Y, Ferro A, et al: Hydrogen sulfide donor GYY4137 protects against myocardial fibrosis. Oxid Med Cell Longev 2015: 691070, 2015.

47. Piechota-Polanczyk A, Kleniewska P and Goraca A: The influence of ETA and ETB receptor blockers on LPS-induced oxidative stress and NF- $\kappa$ B signaling pathway in heart. Gen Physiol Biophys 31: 271-278, 2012.

48. Guo R, Wu K, Chen J, Mo L, Hua X, Zheng D, Chen P, Chen G, $\mathrm{Xu}$ W and Feng J: Exogenous hydrogen sulfide protects against doxorubicin-induced inflammation and cytotoxicity by inhibiting p38MAPK/NFKB pathway in $\mathrm{H} 9 \mathrm{c} 2$ cardiac cells. Cell Physiol Biochem 32: 1668-1680, 2013.

49. Qabazard B, Ahmed S, Li L, Arlt VM, Moore PK and Stürzenbaum SR: C. elegans aging is modulated by hydrogen sulfide and the sulfhydrylase/cysteine synthase cysl-2. PLoS One 8: e80135, 2013.

50. Touyz RM, Yao G, Viel E. Amiri F and Schiffrin EL: Angiotensin II and endothelin-1 regulate MAP kinases through different redox-dependent mechanisms in human vascular smooth muscle cells. J Hypertens 22: 1141-1149, 2004. 